\title{
Multitasking basal cells: combining stem cell and innate immune duties
}

\author{
Renat Shaykhiev
}

Affiliation: Department of Genetic Medicine, Weill Cornell Medical College, New York, NY, USA.

Correspondence: Department of Genetic Medicine, Weill Cornell Medical College, 1300 York Avenue, Box 96, New York, NY 10065, USA. E-mail: geneticmedicinelamed.cornell.edu

0 @ERSpublications

Human airway basal stem cells contribute to host-microbe interactions and innate immunity in the lung http://ow.ly/Q2UAF

The airway epithelium, which covers the luminal surface of the tracheobronchial tree, is a primary barrier that protects the lung from pathogens, irritants, toxic substances and other stressors present in the $\sim 10000 \mathrm{~L}$ of air flowing through the airways every day. This barrier function is normally mediated by differentiated ciliated and secretory cells strategically positioned in the apical layer to interact with the luminal content. Via production of mucus and antimicrobial substances, and continuous beating of the cilia to remove mucus-trapped bacteria and other airborne particles from the airways, these cells protect the lung from respiratory damage and infection [1]. In addition, tight junctions (multiprotein complexes between the apical membrane domains of adjacent differentiated cells) control diffusion of the luminal content across the epithelium, preventing activation of numerous receptors and inflammatory cells enriched in the basolateral compartment or beneath the epithelium $[2,3]$.

However, due to close proximity to the environment, luminal cell populations, especially ciliated cells, are most vulnerable to injury and, as terminally differentiated cells, they are not capable of responding to damage with self-renewal [4]. Thus, maintenance and regeneration of the airway epithelial barrier requires basal cells (BCs) that reside in the basal layer immediately above the basement membrane, to which they firmly attach via hemidesmosomes, a feature that makes this epithelial cell population more resistant to injury. It is particularly relevant to airway repair that BCs operate as stem/progenitor cells capable of self-renewal and differentiation into the entire spectrum of specialised cell populations in the airway epithelium, including ciliated and secretory cells [5].

In a steady state, due to slow turnover of histologically intact airway epithelium, BCs are relatively quiescent. However, in response to injury, airway BCs become activated, acquiring a set of damage-associated phenotypes required for rapid restitution and subsequent regeneration of a normally differentiated epithelial barrier. This process involves changes in the cytoskeleton organisation so that in addition to the keratin (KRT) 5 constitutively expressed by these cells, BCs acquire mesenchymal cell-associated vimentin, various matrix metalloproteinases necessary for migration above the denuded basement membrane, and squamous cell-associated KRT6, KRT13 and KRT14 required for the formation of a provisional barrier [6]. However, for complete repair, the stem/progenitor cell function of airway BCs is required, which involves self-renewal and expansion of BC-derived "early progenitors", also known as intermediate cells, which, under the control of specific niche-derived signals, including those related to the Notch pathway, differentiate into ciliated and secretory cells [5].

Received: March 312015 | Accepted after revision: May 032015

Support statement: R. Shaykhiev is supported, in part, by US National Institutes of Health (National Heart, Lung, and Blood Institute) grants R01 HL107882, R01 HL1189541 and HL123544. Funding information for this article has been deposited with FundRef.

Conflict of interest: None declared.

Copyright OERS 2015 
How do the airways remain protected from pathogens during injury, when differentiated cells normally providing host defense function are damaged and BCs, which are far less "experienced" at mediating hostpathogen interactions, become directly exposed to the outside environment full of microbes? An answer to this question was provided in a recent study by AmATNGALim et al. [7], in which the authors have demonstrated that airway BCs, in addition to their known role as stem/progenitor cells, can serve a unique source of host defense factors. In this study, human airway BCs, but not the differentiated airway epithelium, responded to stimulation with Haemophilus influenzae, a common respiratory pathogen, with upregulation of RNase 7 [7], an antimicrobial protein originally purified from skin keratinocytes [8]. In addition, a number of other innate immune mediators were upregulated in airway BCs, including the antimicrobial peptide human $\beta$-defensin (hBD)-2, lipocalin 2 , the pro-inflammatory cytokines interleukin (IL)- 6 and IL-8, and chemokine CCL20 [7]. Although the role of epithelial cells in mediating innate immune responses has been well established [1,3], the observation that epithelial stem cells, in addition to their role in tissue maintenance and repair, can contribute to innate immune defense is novel, and has important implications for better understanding of both host-microbe interactions and epithelial regeneration.

A number of earlier studies have described airway BCs as a target of respiratory pathogens. An opportunistic pathogen, Pseudomonas aeruginosa, which causes severe respiratory infections in patients with cystic fibrosis and other lung diseases, strongly attaches to KRT13-expressing BCs in the repairing airway epithelium [9]. This binding is mediated by $\alpha 5 \beta 1$ integrin, which is upregulated in airway BCs migrating to the wound area [9]. Once the tight junction barrier is disrupted, a number of viruses can access BCs, including the rhinovirus, which binds intercellular adhesion molecule (ICAM)-1 on proliferating KRT14-expressing BCs [10]. Intriguingly, infection of BCs with rhinovirus upregulates expression of nerve growth factor and its receptor, a marker of airway BC stem cells [11], which is potentially relevant to regulation of $\mathrm{BC}$ survival and further promotion of virus entry [12]. Following airway epithelial injury, airway BC can become infected by the respiratory syncytial virus, which skews BC fate toward the mucus-producing cell lineage and inhibits differentiation into ciliated cells [13], generating the mucous hyperplasia commonly observed in human lung diseases, including asthma and chronic obstructive pulmonary disease (COPD). Challenging this traditional view of airway BCs as merely a target of pathogens employed by the latter to facilitate microbial pathogenesis and infectious tissue injury, Amatngalim et al. [7] provided evidence that airway BCs can sense the presence of pathogens and respond to them with production of antimicrobial factors and cytokines that activate various aspects of immune response, suggesting that BCs can participate in host-microbe interactions as innate immune cells.

The ability of a cell to recognise "non-self" through receptors that sense common microbial patterns rather than specific antigens, a key feature of the innate immunity [14], may have quite a unique meaning when this cell is a tissue stem cell. It could be a strategy that allows stem cells to multitask during the repair process so that a single event, i.e. sensing microbial danger, would allow two protective responses, tissue regeneration and antimicrobial defense, to occur simultaneously in a setting when both responses are equally important. Although Amatngalim et al. [7] did not evaluate the effect of innate immune activation of airway BCs on their ability to kill bacteria or mediate tissue repair, it is known that recognition of microbial patterns by airway epithelial cells via Toll-like receptors (TLRs) can stimulate proliferation and tissue repair [15]. Consistent with this concept, stimulation of Lgr5 intestinal stem cells with bacterial peptidoglycan, a common bacterial motif recognised by the cytosolic innate immune sensor Nod2, protects this stem cell population from oxidative stress-mediated death and potentiates epithelial regeneration [16]. More recently, TLR2 signalling in intestinal and breast epithelial stem cells has been shown to promote the self-renewal and regenerative capacity of these cells [17].

Another interesting observation made by Amatngalim et al. [7] was that transient epithelial damage induced by cigarette smoke increased RNase 7 expression in airway BCs even in the absence of pathogens. This response was dependent on signalling via the epidermal growth factor receptor (EGFR), which is highly expressed in airway BCs [18], and is known to mediate tissue repair and inflammatory cytokine production in the airway epithelium induced by microbial patterns and cigarette smoke $[15,19,20]$, and promote pathologic programming of airway BCs in response to smoking [21]. Thus, augmentation of the BC antimicrobial potential via activation of EGFR signalling may represent a defense response of BCs to injury that prepares this stem/progenitor cell population for possible microbial attack, a common "companion" of tissue damage. A similar strategy has been described for the human epidermis, where sterile injury promotes expression of antimicrobial peptides, including hBD-3, which can protect against the common skin pathogen Staphylococcus aureus [22]. This response is dependent on EGFR activated by heparin-binding epidermal growth factor released from keratinocytes after skin wounding [22]. Further consistent with the role of EGFR in augmenting epithelial host defense in response to injury, EGFR inhibitor, commonly used for treatment of lung cancer, markedly decreases epidermal barrier integrity, RNase 7 expression and antimicrobial activity of human keratinocytes [23]. Not only microbial patterns 


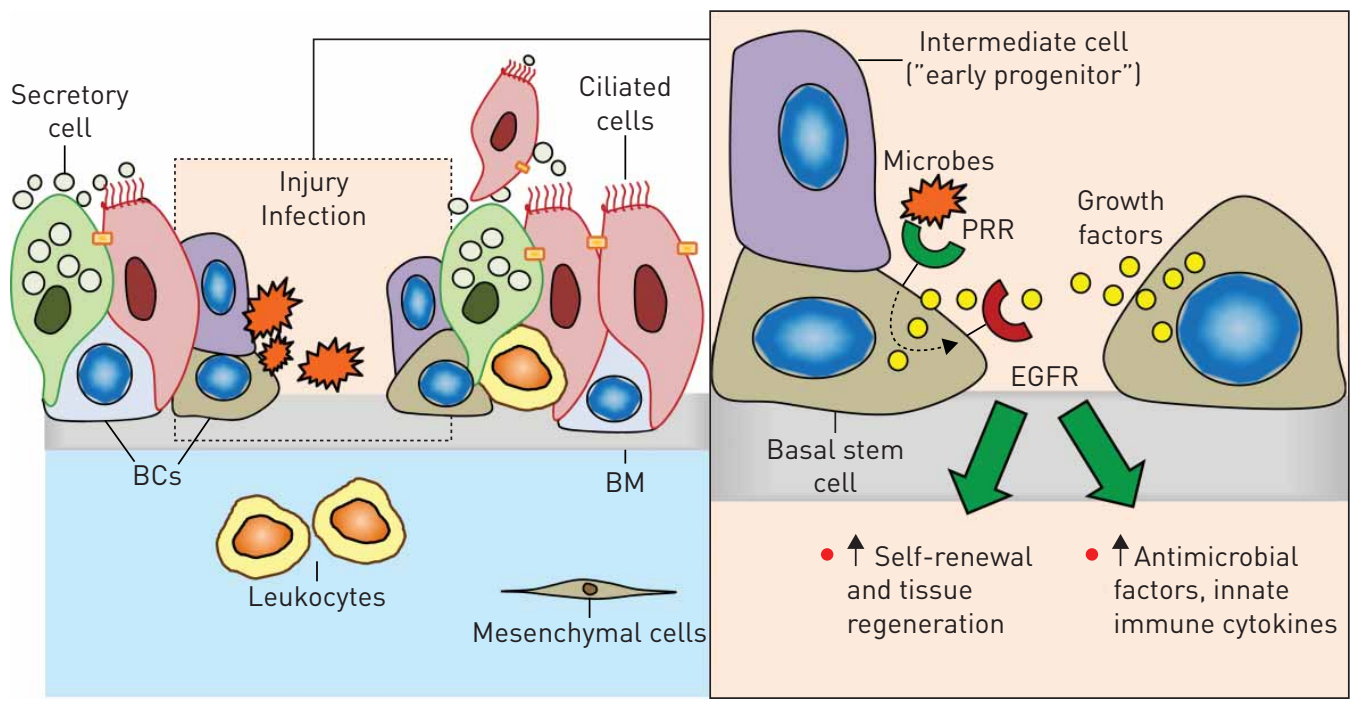

FIGURE 1 Airway basal stem cells (BCs) contribute to tissue regeneration and innate immunity in the airway epithelium. The human airway epithelium is composed of differentiated ciliated and secretory cells, which together provide host defense at the airway epithelial surface under normal conditions, and BCs, the stem/ progenitor cell population residing above the basement membrane (BM). Injury causes damage to differentiated cells, particularly ciliated cells, so that BCs migrate to cover the denuded BM areas and generate intermediate cells, or "early progenitors", that differentiate into ciliated and secretory cells. This process is regulated by the niche signals, including the growth factors upregulated in response to injury, that activate the epidermal growth factor receptor (EGFR) on BCs. In addition, BCs can sense microbes that often accompany injury via pattern-recognition receptors (PRRs), which cooperate with the EGFR signalling to induce expression of antimicrobial peptides/proteins and innate immune cytokines, and further promote tissue regeneration.

and injury but also antimicrobial peptides induced in response to these stimuli promote tissue repair and innate immune cytokine production utilising the EGFR-dependent mechanism [24, 25]. Given that, in addition to EGFR, airway BCs express a broad set of EGFR ligands [26], it is possible that this stem/ progenitor cell population can simultaneously participate in tissue repair and innate immune responses through activation of auto/paracrine EGFR signalling (figure 1).

The novel, innate immune function of airway BC stem cells may be relevant to disease pathogenesis. Disruption of the tight junction barrier, a common feature of asthma and smoking-induced airway disease often mediated by altered EGFR signalling [21, 27, 28], can make airway BCs accessible to pathogens. Persistent activation of innate immune responses in airway BCs through this mechanism may contribute to chronic inflammation characteristic for these disorders. Squamous metaplasia and epithelial-mesenchymal transition-like remodelling generated by airway BCs in response to injury are commonly observed in the airways of patients with COPD and associated with upregulation of inflammatory cytokines, such as IL-1 $\beta$, IL-8 and IL-33 [21, 29, 30]. Exaggerated innate immune signalling in stem/progenitor cells may lead to increased self-renewal, potentially leading to carcinogenesis [17], which is particularly relevant to smoking-induced lung cancer, for which airway BCs are considered the candidate cell of origin [31].

Further understanding of how BCs contribute to host defense and repair in the human airways, and how these two processes are coordinated, will provide important insights into the mechanisms of human lung diseases and identify targets for novel therapeutic approaches to restore the normal airway epithelial barrier in these diseases via normalisation of both stem cell and innate immune functions of airway BCs.

\section{References}

1 Hiemstra PS, McCray PB Jr, Bals R. The innate immune function of airway epithelial cells in inflammatory lung disease. Eur Respir J 2015; 45: 1150-1162.

2 Vermeer PD, Einwalter LA, Moninger TO, et al. Segregation of receptor and ligand regulates activation of epithelial growth factor receptor. Nature 2003; 422: 322-326.

3 Shaykhiev R, Bals R. Interactions between epithelial cells and leukocytes in immunity and tissue homeostasis. J Leukoc Biol 2007; 82: 1-15.

4 Rawlins EL, Ostrowski LE, Randell SH, et al. Lung development and repair: contribution of the ciliated lineage. Proc Natl Acad Sci USA 2007; 104: 410-417.

5 Rock JR, Hogan BL. Epithelial progenitor cells in lung development, maintenance, repair, and disease. Annu Rev Cell Dev Biol 2011; 27: 493-512.

6 Coraux C, Roux J, Jolly T, et al. Epithelial cell-extracellular matrix interactions and stem cells in airway epithelial regeneration. Proc Am Thorac Soc 2008; 5: 689-694. 
7 Amatngalim GD, van Wijck Y, de Mooij-Eijk Y, et al. Basal cells contribute to innate immunity of the airway epithelium through production of the antimicrobial protein RNase 7. J Immunol 2015; 194: 3340-3350.

8 Harder J, Schroder JM. RNase 7, a novel innate immune defense antimicrobial protein of healthy human skin J Biol Chem 2002; 277: 46779-46784.

9 Roger P, Puchelle E, Bajolet-Laudinat O, et al. Fibronectin and $\alpha 5 \beta 1$ integrin mediate binding of Pseudomonas aeruginosa to repairing airway epithelium. Eur Respir J 1999; 13: 1301-1309.

10 Jakiela B, Brockman-Schneider R, Amineva S, et al. Basal cells of differentiated bronchial epithelium are more susceptible to rhinovirus infection. Am J Respir Cell Mol Biol 2008; 38: 517-523.

11 Rock JR, Onaitis MW, Rawlins EL, et al. Basal cells as stem cells of the mouse trachea and human airway epithelium. Proc Natl Acad Sci USA 2009; 106: 12771-12775.

12 Othumpangat S, Regier M, Piedimonte G. Nerve growth factor modulates human rhinovirus infection in airway epithelial cells by controlling ICAM-1 expression. Am J Physiol Lung Cell Mol Physiol 2012; 302: L1057-L1066.

13 Persson $\mathrm{BD}$, Jaffe $\mathrm{AB}$, Fearns R, et al. Respiratory syncytial virus can infect basal cells and alter human airway epithelial differentiation. PLoS One 2014; 9: e102368.

14 Medzhitov R, Janeway CA Jr. Innate immunity: the virtues of a nonclonal system of recognition. Cell 1997; 91: 295-298.

15 Shaykhiev R, Behr J, Bals R. Microbial patterns signaling via Toll-like receptors 2 and 5 contribute to epithelial repair, growth and survival. PLoS One 2008; 3: e1393.

16 Nigro G, Rossi R, Commere PH, et al. The cytosolic bacterial peptidoglycan sensor Nod2 affords stem cell protection and links microbes to gut epithelial regeneration. Cell Host Microbe 2014; 15: 792-798.

17 Scheeren FA, Kuo AH, van Weele LJ, et al. A cell-intrinsic role for TLR2-MYD88 in intestinal and breast epithelia and oncogenesis. Nat Cell Biol 2014; 16: 1238-1248.

18 Shaykhiev R, Zuo WL, Chao I, et al. EGF shifts human airway basal cell fate toward a smoking-associated airway epithelial phenotype. Proc Natl Acad Sci USA 2013; 110: 12102-12107.

19 Koff JL, Shao MX, Ueki IF, et al. Multiple TLRs activate EGFR via a signaling cascade to produce innate immune responses in airway epithelium. Am J Physiol Lung Cell Mol Physiol 2008; 294: L1068-L1075.

20 Richter A, O'Donnell RA, Powell RM, et al. Autocrine ligands for the epidermal growth factor receptor mediate interleukin-8 release from bronchial epithelial cells in response to cigarette smoke. Am J Respir Cell Mol Biol 2002; 27: 85-90.

21 Shaykhiev R, Crystal RG. Early events in the pathogenesis of chronic obstructive pulmonary disease. Smoking-induced reprogramming of airway epithelial basal progenitor cells. Ann Am Thorac Soc 2014; 11: Suppl. 5, S252-S258

22 Sorensen $\mathrm{OE}$, Thapa DR, Roupe KM, et al. Injury-induced innate immune response in human skin mediated by transactivation of the epidermal growth factor receptor. J Clin Invest 2006; 116: 1878-1885.

23 Lichtenberger BM, Gerber PA, Holcmann M, et al. Epidermal EGFR controls cutaneous host defense and prevents inflammation. Sci Transl Med 2013; 5: 199 ra111.

24 Tjabringa GS, Aarbiou J, Ninaber DK, et al. The antimicrobial peptide LL-37 activates innate immunity at the airway epithelial surface by transactivation of the epidermal growth factor receptor. J Immunol 2003; 171: 6690-6696.

25 Shaykhiev R, Beisswenger C, Kandler K, et al. Human endogenous antibiotic LL-37 stimulates airway epithelial cell proliferation and wound closure. Am J Physiol Lung Cell Mol Physiol 2005; 289: L842-L848.

26 Hackett NR, Shaykhiev R, Walters MS, et al. The human airway epithelial basal cell transcriptome. PLoS One 2011; 6: e18378.

27 Davies DE. Epithelial barrier function and immunity in asthma. Ann Am Thorac Soc 2014; 11: Suppl. 5, S244-S251.

28 Vallath S, Hynds RE, Succony L, et al. Targeting EGFR signalling in chronic lung disease: therapeutic challenges and opportunities. Eur Respir J 2014; 44: 513-522.

29 Araya J, Cambier S, Markovics JA, et al. Squamous metaplasia amplifies pathologic epithelial-mesenchymal interactions in COPD patients. J Clin Invest 2007; 117: 3551-3562.

30 Byers DE, Alexander-Brett J, Patel AC, et al. Long-term IL-33-producing epithelial progenitor cells in chronic obstructive lung disease. J Clin Invest 2013; 123: 3967-3982.

31 Fukui T, Shaykhiev R, Agosto-Perez F, et al. Lung adenocarcinoma subtypes based on expression of human airway basal cell genes. Eur Respir J 2013; 42: 1332-1344. 